\title{
Effectiveness of the cricket transformation process in increasing representation and performance of black cricketers at provincial level in South Africa
}

\author{
M Sharhidd Taliep (PhD) \\ Department of Sport Management, Cape Peninsula University of Technology, Cape Town
}

\begin{abstract}
Objectives. This study investigates the effectiveness of the cricket transformation process in firstly increasing representation of black players and secondly improving performance of black players in the South African 4-day provincial competition between the 1996/1997 and 2007/2008 cricket seasons.

Methods. Cricketers were categorised as white, black African or coloured/Indian. Whenever the category 'black' is mentioned alone, it refers to black African and coloured/Indian. All data were obtained from www.cricinfo.com.

Results. The number of white players decreased and the number of black African and coloured/Indian players increased between the 1996/1997 and 2007/2008 seasons. White batsmen had significantly higher batting averages than black Africans, but were only better than coloureds/Indians in the 2001/2002 season. Coloureds/Indians had better batting averages than black Africans in all seasons except 2001/2002 and 2004/2005. There was a significant improvement in the batting averages of coloureds/lndians but not of whites and black Africans over the 12 seasons. White bowlers had significantly better bowling averages than coloured/Indian bowlers for seasons 2002/2003, 2004/2005 and 2006/2007. There were no significant differences in the bowling averages between white and black African players and between coloured/Indian and black African players over the 12 seasons. There was a tendency towards a decreased bowling performance for coloureds/Indians, whereas there was no significant decrement in the bowling performance for whites and black Africans over the 12 seasons.

Conclusion. The increase in the number of black cricketers performing according to standard suggests a reasonable successful transformation process. However, representation and batting performance of black African batsmen remain a concern.
\end{abstract}

\section{CORRESPONDENCE:}

\section{Sharhidd Taliep}

Department of Sport Management

Cape Peninsula University of Technology

PO Box 652

Cape Town 8000

E-mail: talieps@cput.ac.za

\section{Introduction}

The classification of South Africans into racial populations was established during apartheid to discriminate and legalise racial segregation. South African citizens have consequently suffered from racial labelling. Racial controversies smear the newpapers regularly and cricket players' careers have at times been adversely affected. ${ }^{1-3}$ It is hoped that South Africa will reach a stage where race does not play a role in sport and team selection is based only on merit. It is further hoped that these teams are representative of all South Africans. How far is South Africa from reaching this goal in cricket? To answer this question, racial classifications used by the South African Government and the current cricket controlling body, Cricket South Africa (CSA), were employed. Many have argued against the validity of using race as a classification, especially in medical research, as genetic similarities between races far outweigh the differences. ${ }^{4,5}$ However, to understand the progression of cricketers who have been disadvantaged because of apartheid, it is necessary to racially categorise players. According to the Broad-Based Black Economic Empowerment Act ${ }^{6}$ and CSA, ${ }^{7}$ the word 'black' is used for all people African, coloured or Indian. However, the words 'black African' are also used and refer to blacks who were historically worst disadvantaged. ${ }^{7,8}$ Therefore, to adhere to the policy of CSA, but also to distinguish between black African and other black players (coloured and Indian), the following categorisation will be used in this article: white, coloured/Indian and black African. CSA does not distinguish between coloureds and Indians and therefore they were pooled into a single group.

In 1991, at the start of the cricket unification process (the merger of all racial populations under one cricketing body), the United Cricket Board of SouthAfrica (UCBSA) was formed. UCBSAneeded to redress the injustices caused by apartheid to transform South African cricket to be representative of all South Africans. ${ }^{9}$ Consequently, a National Transformation Charter and Pledge to the Nation was adopted in 1998 by the UCBSA. ${ }^{8}$ This charter covered 10 fundamental areas or thrusts. One of the main aims of the transformation process is highlighted in the thrust 'Redress and Representivity'. This states that it is: 'Our historic and moral duty to ensure that cricket grows and flourishes among the truly disadvantaged of society, with the recognition that the majority of disadvantaged come from our black African communities. This involves a commitment to develop potential among our black African people at all levels of the game. This programme reaffirms our mission to bring cricket to all the people of South Africa and facilitate a culture of non-racialism. ${ }^{8}$

To achieve this, UCBSA started a development and targeted transformation programme. The development programme aimed at developing disadvantaged communities. Development of facilities, coaches, administrators and cricketing skill was primary on the 
agenda. ${ }^{10-12}$ UCBSA spent an enormous amount of money on this and in 2002 the UCBSA's operational budget for development was R154 million. ${ }^{11}$ The belief was that developing the infrastructures and resources of previously disadvantaged communities would result in improved performance and skill enhancement within the communities. The result envisaged was a provincial and national team representing all South Africans.

Transformation targets are an important part of the vision and policy of CSA and a South African constitutional requirement. ${ }^{13}$ Currently, CSA subscribes to targeted transformation set for all representative cricket, i.e. that in all national and provincial teams a certain target of black players should be reached. The transformation policy target of CSA for the national and franchise (provincial) teams is 4 black players. ${ }^{7,8}$ If this target is not reached, an explanation should be provided to the president of CSA. If the president does not accept the explanation, he has the power of veto. ${ }^{8}$ This transformation policy has often resulted in controversy. ${ }^{1-3}$ One of the most contentious of these relates to Charl Langeveldt and Andre $\mathrm{Nel}$ in 2008. Charl Langeveldt, a coloured fast bowler, was allegedly selected to replace Andre $\mathrm{Nel}$, a white fast bowler, to achieve a transformational target. ${ }^{1}$ Langeveldt, upon hearing this, quit the touring squad to India. Another example is South African born Kevin Peterson who believed that the transformation process in South Africa hindered his chances of playing for the South African national team. ${ }^{3}$ Consequently, he left to play cricket in England. The aim of this study is not to delve into these controversies surrounding transformation. It is imperative though to monitor the success of this transformation process to accurately determine its effectiveness in producing skilled and competent black cricketers in South Africa One way to monitor the success of transformation is to observe the change in the number of black players over time. Another way is to observe the change in their performance over time.

The aim of this study is therefore to present data of all South African cricket players participating in the 4-day provincial competitions (currently referred to as the SuperSport Series) over the past 12 seasons (from the 1996/1997 to the 2007/2008 cricket seasons) - firstly to observe how the numbers of players have changed, and secondly to observe how their performances have progressed. The results of this study will provide insight into the success of the cricket transformation process in South Africa.

\section{Methods}

All data were taken from www.cricinfo.com and reflect all cricketers participating (including national players) in the 4-day provincial competitions between the 1996/1997 and the 2007/2008 cricket seasons. A batsman was defined as any player who batted in a match. A bowler was defined as any player who bowled in a match. However, it is possible that certain racial populations are more suited to a particular skill in cricket. For example, black Africans might be more suited to bowling than batting. If this is the case, their low batting averages would not truly reflect the performance of the black Africans who were selected for the main purpose of batting. Therefore, specialist batsmen and specialist bowlers were also classified. Specialist batsmen were classified as players who regularly bat from position 1 - 7 in the batting line-up. A specialist bowler was classified as a player who regularly bowls in matches. Batting average was defined by the average number of runs per batting inning. Higher batting averages represent better batting performance. Bowling average was defined as the average number of runs conceded per wicket taken. Lower bowling averages represent better bowling performance. The number of cricket teams playing in the provincial competition changed on three occasions between 1996/1997 and
$2007 / 2008$. From the $1996 / 1997$ to the $1998 / 1999$ season there were 9 teams, from the $1999 / 2000$ to the 2003/2004 season there were 11 teams, and from the 2004/2005 to the 2007/2008 season there were only 6 teams.

\section{Statistical analyses}

To observe the change in the number of players over time, the average number of players per team was presented. Linear regression analysis was used to compare the change in the number of white, coloured/Indian and black African players per team across the 12 seasons. Linear regression analysis was also used to compare the change in the median batting and bowling performance over the 12 seasons. Medians were used instead of means for these regression analyses because before the 2000/2001 season the number of black

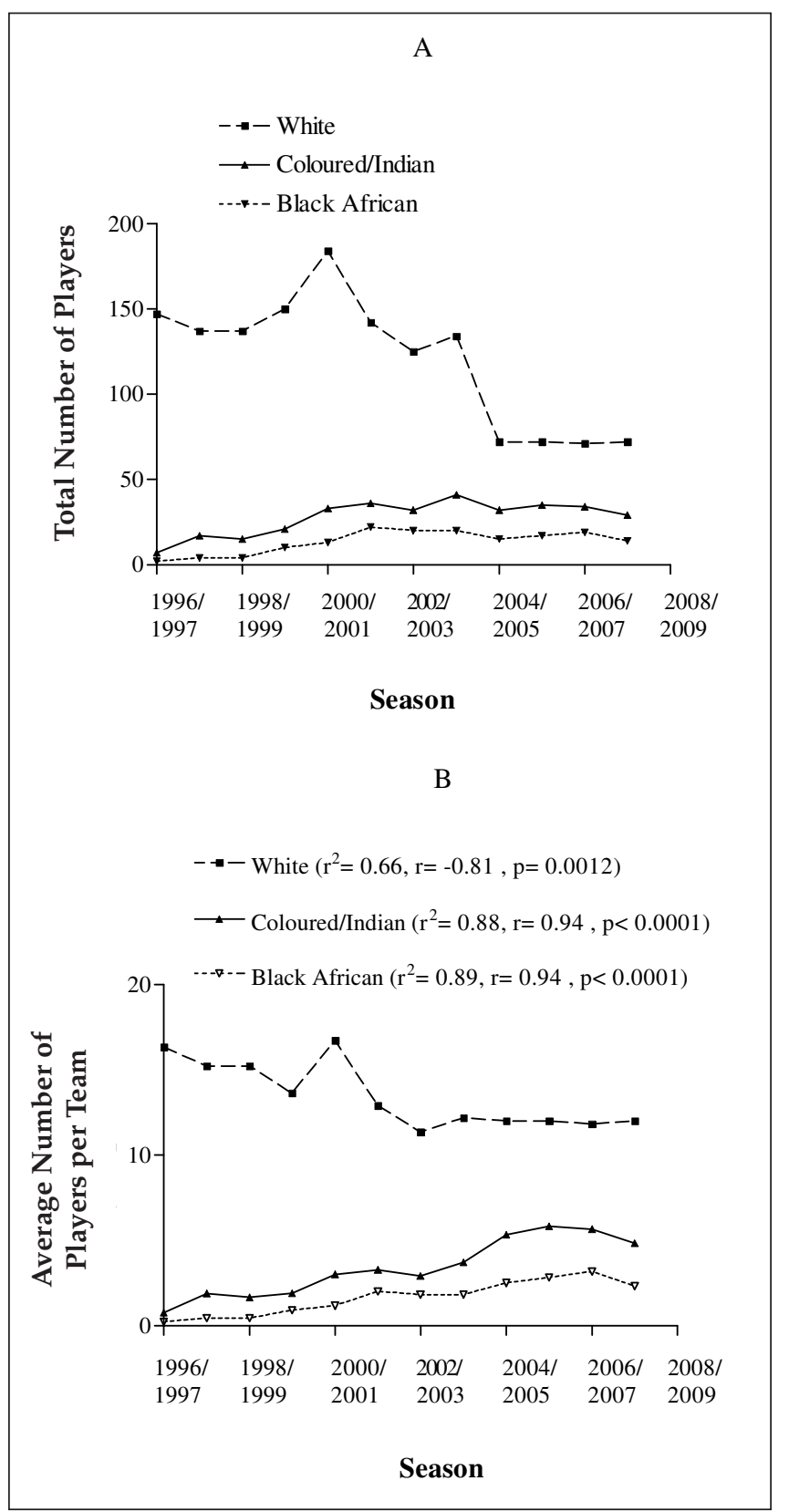

Fig. 1 (A). Representation of the total number of players in the 4-day provincial competition across the 12 seasons, and (B) representation of the average number of players per team in the 4-day provincial competition across the 12 seasons. 


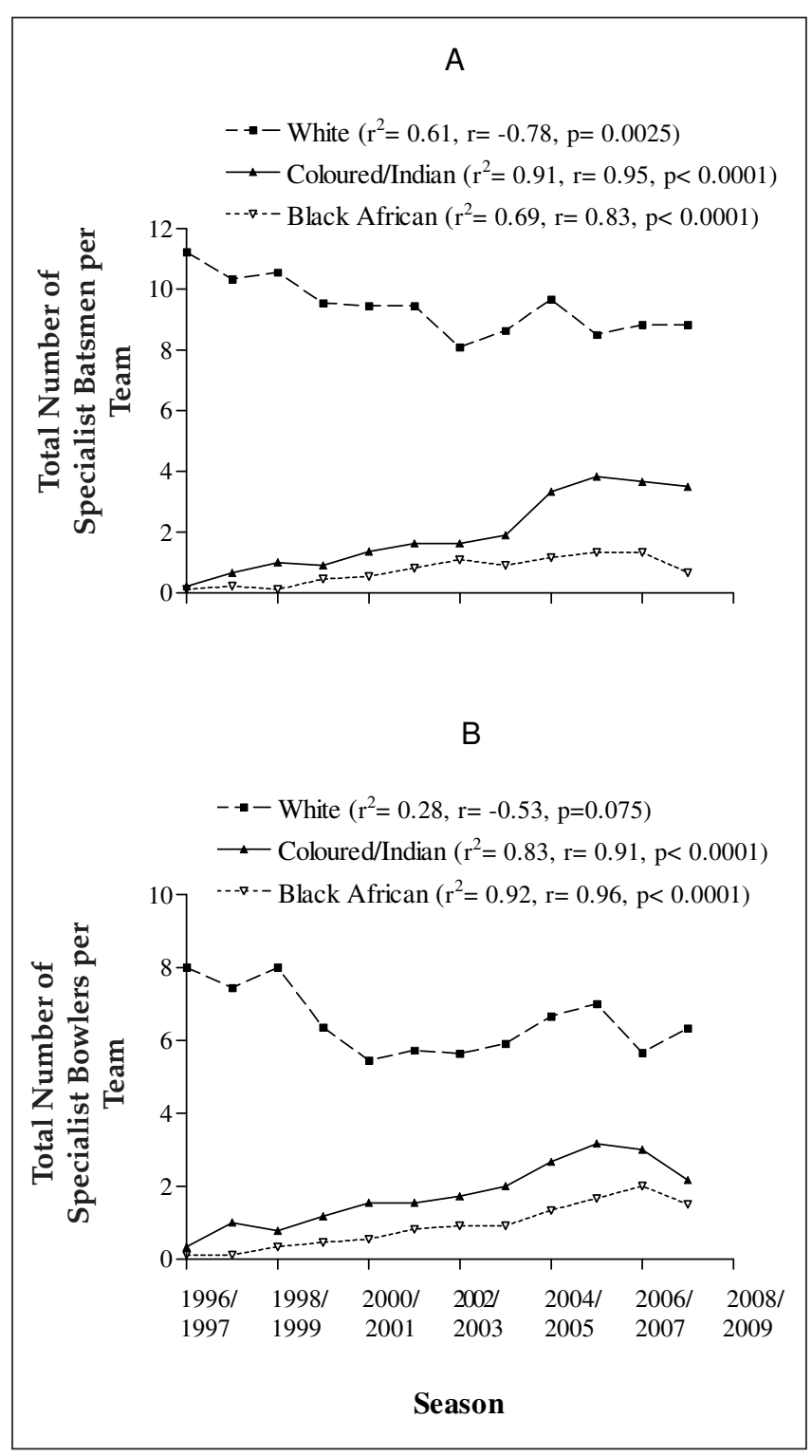

Fig. 2 (A). Representation of the total number of specialist batsmen, and (B) representation of the specialist bowlers per team participating in the 4-day provincial competition across the 12 seasons.

Africans and coloureds/Indians was small and their data were not normally distributed. Univariate analysis of variance was used to determine the difference between the mean batting and bowling performance of the different racial populations between the 2000/2001 and 2007/2008 seasons. Univariate analysis was not done on the data before the 2000/2001 season because of the very small number of black African players. Significant difference was set at $p<0.05$. When the data accounted for specialist batsmen and bowlers, the sample size was often too small for statistical comparisons between populations. The median specialist batsmen and bowlers' performance data were therefore presented across the 12 seasons without any further statistical analysis.

\section{Results}

\section{Total number of players}

The total number of players in each cricket season is presented in Fig. 1A. In the 1996/1997 season there were 147 white, but only

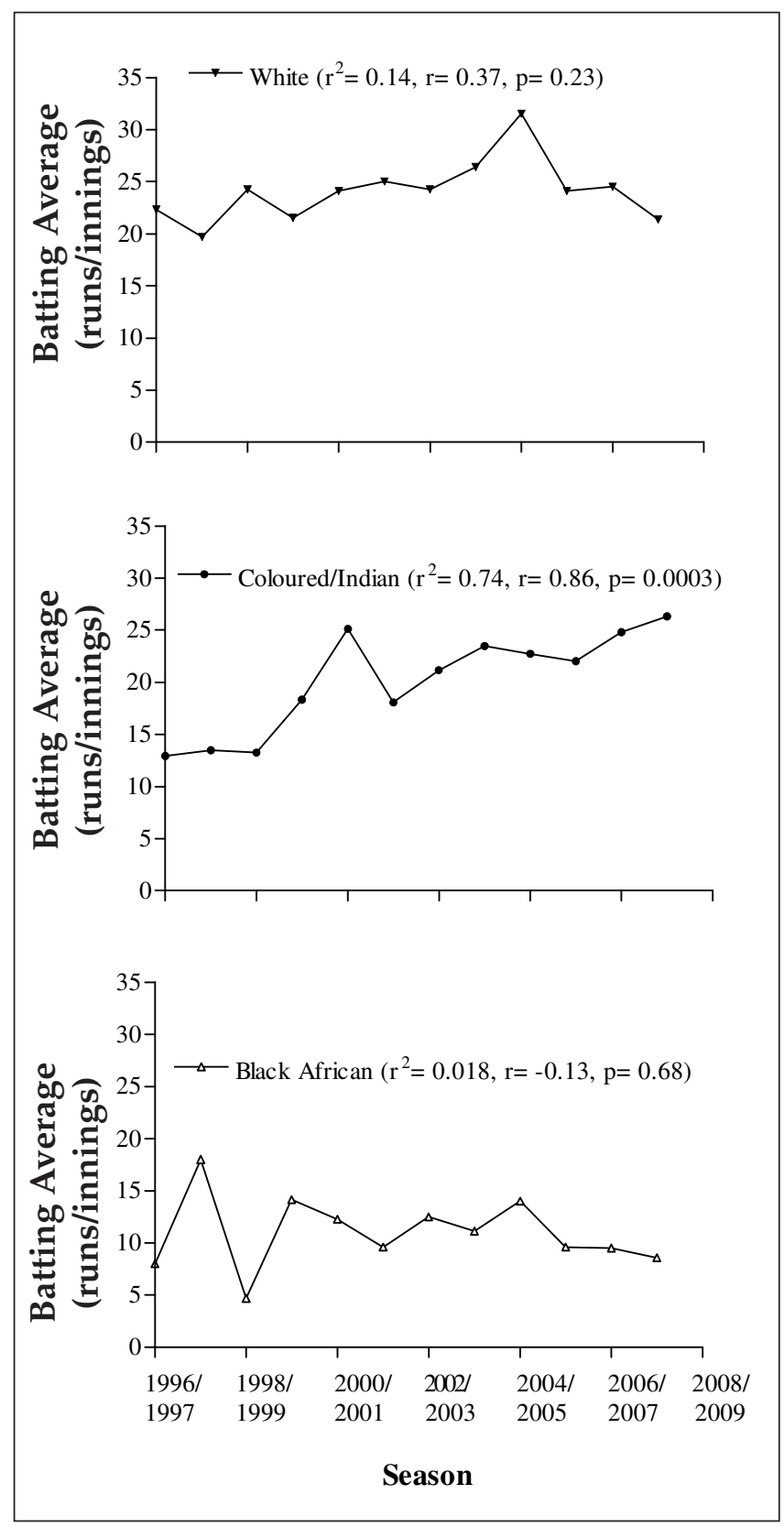

Fig. 3. Regression analysis of the median batting performance across the 12 seasons.

7 coloured/Indian and 2 black African players participating in 4-day matches. In the 2007/2008 season there were 72 white, 29 coloured/ Indian and 14 black African players. The results of the linear regression analysis indicate a significant decrease in the number of white players per team $\left(r^{2}=0.66, r=-0.81, p=0.0012\right)$ and a significant increase in the number of coloured/Indian $\left(r^{2}=0.89, r=0.94, p<0.0001\right)$ and black African $\left(r^{2}=0.88, r=0.94, p<0.0001\right)$ players per team across the 12 seasons (Fig. 1B).

The total numbers of specialist batsmen and bowlers per team are presented in Fig. 2. There was a significant decrease in the number of specialist white batsmen per team $\left(r^{2}=0.61, r=-0.78, p=0.0025\right)$ and a significant increase in the number of coloured/Indian $\left(r^{2}=0.91\right.$, $r=0.95, p<0.0001)$ and black African specialist batsmen per team $\left(r^{2}=0.69, r=0.83, p<0.0001\right)$ (Fig. 2A). There was a non-significant decrease in the number of specialist white bowlers per team $\left(r^{2}=0.28\right.$, $r=-0.53, p=0.075)$, while both coloureds/Indians $\left(r^{2}=0.83, r=0.91\right.$, 


\begin{tabular}{|c|c|c|c|c|}
\hline Season & Race & Mean batting average (runs/innings) & $p$-value & $95 \% \mathrm{Cl}$ \\
\hline \multirow[t]{3}{*}{$2000 / 2001$} & White v. coloured/Indian & 26.1 v. 26.0 & 0.963 & $-7.0,7.4$ \\
\hline & White v. black & 26.1 v. 11.0 & $0.007^{*}$ & $4.1,26.2$ \\
\hline & Coloured/Indian v. black & 26.0 v. 11.0 & $0.019^{*}$ & $2.5,27.5$ \\
\hline \multirow[t]{3}{*}{$2001 / 2002$} & White v. coloured/Indian & 28.8 v. 22.0 & $0.043^{*}$ & $0.22,13.5$ \\
\hline & White v. black & 28.8 v. 15.3 & $0.002^{*}$ & $5.1,22.0$ \\
\hline & Coloured/Indian v. black & 22.0 v. 15.3 & 0.183 & $-3.2,16.5$ \\
\hline \multirow[t]{3}{*}{$2002 / 2003$} & White v. coloured/Indian & 28.8 v. 30.4 & 0.654 & $-8.6,5.4$ \\
\hline & White v. black & 28.8 v. 14.6 & $0.001^{*}$ & $5.6,30.0$ \\
\hline & Coloured/Indian v. black & 30.6 v. 14.6 & $0.002^{*}$ & $5.6,26.1$ \\
\hline \multirow[t]{3}{*}{$2003 / 2004$} & White v. coloured/Indian & 30.6 v. 25.1 & 0.088 & $-0.8,11.9$ \\
\hline & White v. black & 30.6 v. 13.4 & $0.000^{*}$ & $8.8,25.7$ \\
\hline & Coloured/Indian v. black & 25.1 v. 13.4 & $0.018^{*}$ & $2.0,21.3$ \\
\hline \multirow[t]{3}{*}{$2004 / 2005$} & White v. coloured/Indian & 32.4 v. 25.2 & 0.066 & $-0.5,14.9$ \\
\hline & White v. black & 32.4 v. 19.8 & $0.020^{*}$ & $2.0,23.3$ \\
\hline & Coloured/Indian v. black & 25.2 v. 19.8 & 0.365 & $-6.3,17.1$ \\
\hline \multirow[t]{3}{*}{$2005 / 2006$} & White v. coloured/Indian & 26.5 v. 24.1 & 0.524 & $-5.0,9.9$ \\
\hline & White v. black & 26.5 v. 12.7 & $0.009^{*}$ & $3.5,24.1$ \\
\hline & Coloured/Indian v. black & 24.1 v. 12.7 & $0.047^{*}$ & $0.2,22.7$ \\
\hline \multirow[t]{3}{*}{$2006 / 2007$} & White v. coloured/Indian & 27.7 v. 27.6 & 0.976 & $-7.3,7.5$ \\
\hline & White v. black & 27.7 v. 12.5 & $0.001^{*}$ & $5.9,24.5$ \\
\hline & Coloured/Indian v. black & 27.6 v. 12.5 & $0.004^{*}$ & $4.8,25.4$ \\
\hline \multirow[t]{3}{*}{$2007 / 2008$} & White v. coloured/Indian & 25.5 v. 25.9 & 0.985 & $-7.6,7.8$ \\
\hline & White v. black & 25.9 v. 9.8 & $0.003^{*}$ & $5.4,26.0$ \\
\hline & Coloured/Indian v. black & 25.9 v. 9.8 & $0.006^{*}$ & $4.6,27.6$ \\
\hline
\end{tabular}

$p<0.0001)$ and black Africans $\left(r^{2}=0.92, r=0.96, p<0.0001\right)$ presented a significant increase in the number of specialist bowlers per team (Fig. 2B).

\section{Batting averages}

White batsmen had significantly higher batting averages than black African batsmen in every season (Table I). However, it was only in the 2001/2002 season that the batting average of whites was significantly better than that of coloureds/Indians ( 28.7 v. 22.0 runs/innings, $p=0.047$ ) (Table I). Coloureds/Indians had superior batting averages than black Africans in all seasons except in 2001/2002 (22.0 v. 15.3 runs/innings, $p=0.183$ ) and 2004/2005 (25.2 v. 19.8 runs/innings, $p=0.365$ ). The results of the linear regression analysis (Fig. 3) indicate a significant improvement in the batting averages for the coloured/Indian batsmen $\left(r^{2}=0.74, r=0.86, p=0.0003\right)$ but not for whites $\left(r^{2}=0.14, r=0.37, p=0.23\right)$ and black Africans $\left(r^{2}=0.018\right.$, $r=-0.13, p=0.68)$. The specialist batting performance data are presented in Fig. 4. Although no further statistical comparisons were made between racial populations, it appears as if batting averages of white and coloured/Indian specialist batsmen are better than those of black Africans in most seasons.

\section{Bowling averages}

White bowlers had significant better bowling averages than coloured/Indian bowlers for seasons 2002/2003 (35.5 v. 50.1 runs/ wicket, $p=0.045), 2004 / 2005$ (37.9 v. 55.4 runs/wicket, $p=0.038$ ) and 2006/2007 (37.1 v. 59.8 runs/wicket, $p=0.004$ ) (Table II). There were no significant differences in the bowling averages between whites and black Africans and between coloureds/Indians and black Africans across the 12 seasons. The results of the linear regression analysis (Fig. 5) indicate a tendency for a decreased bowling performance for coloureds/Indians $\left(r^{2}=0.32, r=0.56, p=0.06\right)$, but no significant differences in the bowling averages for whites $\left(r^{2}=0.16, r=-0.4, p=0.2\right)$ and black Africans $\left(r^{2}=0.01, r=-0.11, p=0.73\right)$ across the 12 seasons.

The specialist bowlers' performance data are presented in Fig. 6. Except for the 2002/2003, 2004/2005 and 2006/2007 seasons, where white players appear to have better bowling averages than coloured/Indian players, there are no major differences between the specialist bowling performances of the three racial populations.

\section{Discussion}

The increase in the number of coloured/Indian and black African players is not surprising because of the transformation policy aimed at having a certain target of black players for provincial and national cricket. However, the success of transformation lies in the ability to perform to the standard of cricket required, otherwise it is merely 'window dressing'. ${ }^{8}$ The performance of these players was, therefore, investigated. From the 2002/2003 season the performances of coloured/Indian batsmen were on a par with those of white bats- 


\begin{tabular}{|c|c|c|c|c|}
\hline Season & Race & Mean bowling average (runs/innings) & $p$-value & $95 \% \mathrm{Cl}$ \\
\hline \multirow[t]{3}{*}{$2000 / 2001$} & White v. coloured/Indian & 37.8 v. 33.0 & 0.520 & $-10.1,20.0$ \\
\hline & White v. black & 37.8 v. 46.4 & 0.484 & $-32.3,15.3$ \\
\hline & Coloured/Indian v. black & 33.0 v. 46.4 & 0.324 & $-40.2,13.3$ \\
\hline \multirow[t]{3}{*}{$2001 / 2002$} & White v. coloured/Indian & 38.9 v. 38.5 & 0.958 & $-13.8,14.6$ \\
\hline & White v. black & 38.9 v. 31.9 & 0.488 & $-12.8,26.9$ \\
\hline & Coloured/Indian v. black & 38.5 v. 31.9 & 0.565 & $-16.0,29.2$ \\
\hline \multirow[t]{3}{*}{$2002 / 2003$} & White v. coloured/Indian & 35.5 v. 50.1 & $0.045^{*}$ & $-29.0,-0.3$ \\
\hline & White v. black & 35.5 v. 39.3 & 0.704 & $-23.8,16.1$ \\
\hline & Coloured/Indian v. black & 50.1 v. 39.3 & 0.350 & $-11.8,33.4$ \\
\hline \multirow[t]{3}{*}{$2003 / 2004$} & White v. coloured/Indian & 40.8 v. 39.1 & 0.788 & $-11.1,14.7$ \\
\hline & White v. black & 40.8 v. 44.4 & 0.699 & $-21.8,14.6$ \\
\hline & Coloured/Indian v. black & 39.1 v. 44.4 & 0.603 & $-25.6,14.9$ \\
\hline \multirow[t]{3}{*}{$2004 / 2005$} & White v. coloured/Indian & 37.9 v. 55.4 & $0.038^{*}$ & $-34.0,-1.0$ \\
\hline & White v. black & 37.9 v. 41.2 & 0.766 & $-25.0,18.4$ \\
\hline & Coloured/Indian v. black & 55.4 v. 41.2 & 0.253 & $-10.2,38.6$ \\
\hline \multirow[t]{3}{*}{$2005 / 2006$} & White v. coloured/Indian & 45.7 v. 48.6 & 0.712 & $-18.0,12.3$ \\
\hline & White v. black & 45.7 v. 38.4 & 0.445 & $-11.6,26.3$ \\
\hline & Coloured/Indian v. black & 48.6 v. 38.4 & 0.342 & $-10.9,31.4$ \\
\hline \multirow[t]{3}{*}{$2006 / 2007$} & White v. coloured/Indian & 37.1 v. 59.8 & $0.004^{*}$ & $-38.2,-7.1$ \\
\hline & White v. black & 37.1 v. 42.9 & 0.585 & $-26.7,15.1$ \\
\hline & Coloured/Indian v. black & 59.8 v. 42.9 & 0.143 & $-5.7,39.5$ \\
\hline \multirow[t]{3}{*}{$2007 / 2008$} & White v. coloured/Indian & 29.5 v. 37.1 & 0.382 & $-24.9,9.6$ \\
\hline & White v. black & 29.5 v. 40.9 & 0.207 & $-29.2,6.4$ \\
\hline & Coloured/Indian v. black & 37.1 v. 40.9 & 0.736 & $-25.4,18.0$ \\
\hline
\end{tabular}

men. White batsmen were able to maintain a similar batting average across the 12 seasons, while coloured/Indian batsmen significantly improved their batting performance. This can be seen as a transformation success for coloured/Indian batsmen as both their numbers and their performances have significantly improved. However, black African batsmen have weaker batting averages than coloureds/Indians and whites. More concerning is that there has been no significant improvement in the batting performance over the 12 seasons. Even when only specialist batsmen are considered, black African batting performance is generally below the standard of their white and coloured/Indian counterparts. Furthermore, in the 2007/2008 season only 4 specialist black African batsmen ( 0.7 per team, Fig. 2A) participated in the 4-day provincial competition. This represented the lowest number of specialist batsmen participating per team since the 2000/2001 season. It is difficult to isolate a particular reason for their poor batting performance and their poor representation in 4-day provincial cricket. It can be speculated that because batting equipment is expensive, black Africans, who were disadvantaged the most during apartheid, cannot afford the equipment required to train effectively. Despite this handicap great cricketers have successfully trained with basic equipment. ${ }^{14}$

The performance of black African bowlers was not significantly different to that of white or coloured/Indian bowlers. Similarly, black African specialist bowlers' performances do not appear to be below the standard of whites and coloureds/Indians. The similarity

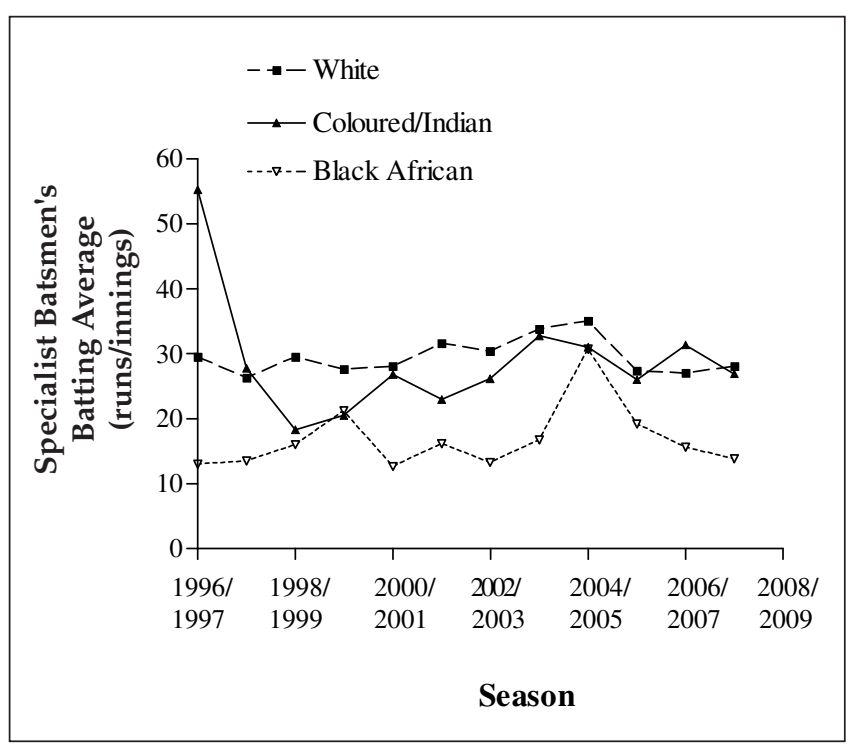

Fig. 4. Comparison of the median batting performances of the different racial populations across the 12 seasons for the specialist batsmen.

in performance appears to date back to the 1996/1997 season (although the data were not analysed statistically because of the 


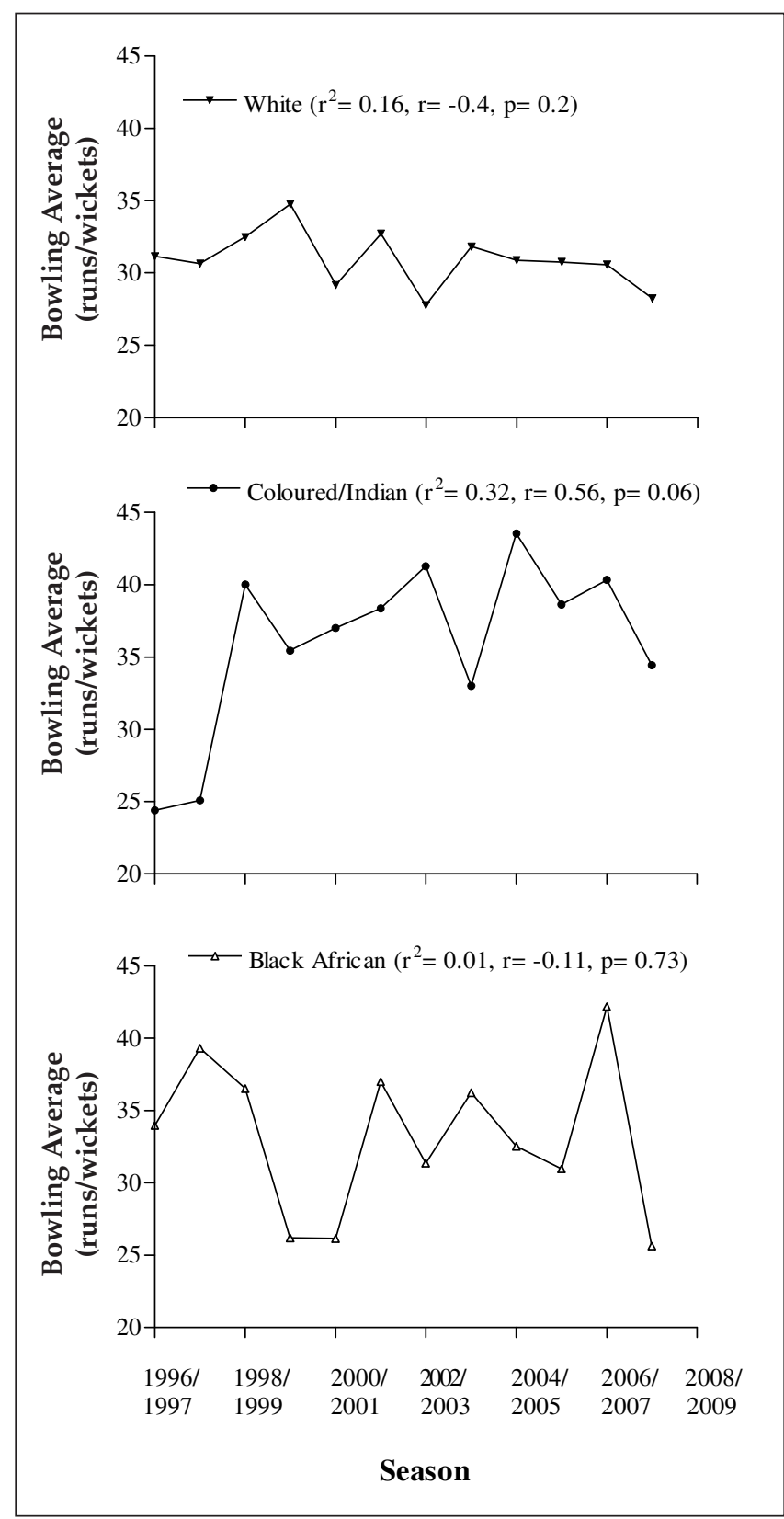

Fig. 5. Regression analysis of the median bowling performance across the 12 seasons.

small sample size) and suggests a traditional strength in performance among black Africans, rather than a process of improvement. This is substantiated in the regression analysis results, which indicate no significant improvement in the performance of black African bowlers and specialist bowlers since the 1996/1997 season. Fast bowler Makhaya Ntini is a role model for black Africans. Ntini was the first black African to represent South Africa and became one of South Africa's best fast bowlers. His success could have inspired other black Africans to reach similar heights. It is also possible that black African bowlers are more fatigue resistant. There is evidence that black South African endurance runners are more resistant to fatigue than their white counterparts. ${ }^{15}$ This study indicates that the time to fatigue during a repetitive isometric muscle contraction was longer in black Africans than in whites. Bowling performance has been shown to decrease after a long bowling spell. ${ }^{16}$ It is therefore possible that black African bowlers are more fatigue resistant, allowing them to

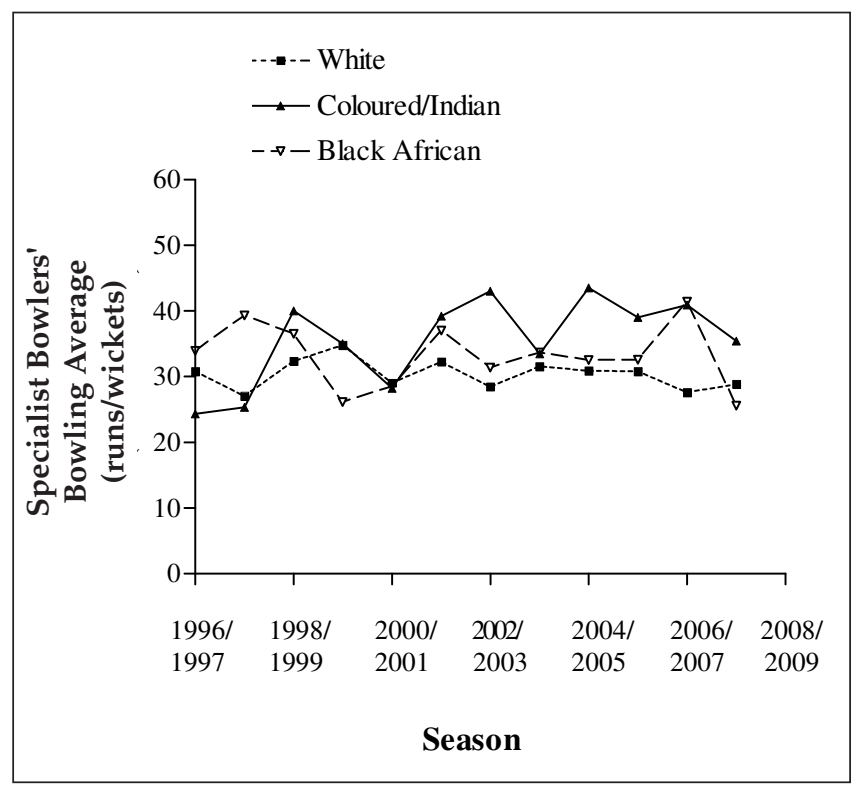

Fig. 6. Comparison of the median bowling performances of the different racial populations across the 12 seasons for the specialist bowlers.

sustain high performances over extended periods. This could be a reason why the majority of black African bowlers are specialist bowlers. However, this is speculative and requires investigating.

Coloured/Indian bowling performances were significantly weaker than those of whites during the 2002/2003, 2004/2005 and 2006/2007 seasons. Furthermore, there was a tendency for a decrement in their performance from the 1996/1997 season for all bowlers and a significant decrease in bowling performance among the specialist bowlers. There is no clear reason why their bowling performance would decrease over the 12 years. However, it is possible that the decrement in performance from 1996 to 2008 is a result of good bowling performances in the 1996/1997 and 1997/1998 seasons that were never matched again. Further investigation into the possible causes of the decrement in performance is required.

\section{Conclusion}

The transformation process has been fairly effective in increasing the number of black players. The performance of coloured/Indian batsmen and black African bowlers is on a par with that of whites. However, the major concern is that there are few specialist black African batsmen participating in 4-day provincial cricket and that their batting performance is below standard. If this imbalance is addressed, South African provincial team selection could be purely on merit with no reference to race.

\section{Acknowledgements}

I would like to thank Professor Simeon Davies, Miss Bridget Parr and Miss Zizonke Sigodi for their assistance and advice with regard to this article. A special thanks to Mrs Corrie Uys for her assistance with the statistics.

\section{References}

1. Adams Z. Arendse on the Nel/Langeveldt fiasco. The Cape Times 30 May 2008:27.

2. Cowley J. Apartheid, not the ruling regime, brought race into South Africa New Statesman 7 February 2005:59. 
3. Main B. Colour-coded Proteas choice is black and white for some but a grey area for others. Goal Coast Bulletin 16 December 2008:53.

4. Kirsch R. Welcome to the World Medical Association. S Afr Med J 2006;96:1003-1005.

5. Sheldon T, Parker H. Race and ethnicity in health research. J Public Health Med 1992;14:104-110.

6. Broad-Based Black Economic Empowerment Act No. 53, 2003. http:// www.info.gov.za/view/DownloadFileAction?id=68031 (accessed 6 August 2009).

7. Parliamentary Monitoring Group. Cricket SA: Transformation policy: Selection of national cricket team. http://www.pmg.org.za/report/20080226cricket-sa-transformation-policy-selection-national-cricket-team (accessed 10 September 2008)

8. Parliamentary Monitoring Group. Cricket SA: Transformation policy: Selection of national cricket team. Transformation background. http://www. pmg.org.za/files/docs/080226csa.pdf (accessed 6 October 2008).

9. The United Cricket Board of South Africa. Mission: The principles, aims and objectives of the UCB. http://static.cricinfo.com/db/NATIONAL/RSA ABOUT_THE_UCB/ (accessed 10 September 2009).
10. Parliamentary Monitoring Group. United Cricket Board of South Africa: Briefing. http://www.pmg.org.za/minutes/20010910-united-cricket-boardsouth-africabriefing (accessed 6 August 2009).

11. UCBSA Presentation Group. Presentation by the United Cricket Board of South Africa to the Parliamentary Portfolio Committee on Sports and Recreation. http://www.pmg.org.za/docs/2002/appendices/020903ucb. ppt (accessed 6 August 2009).

12. Smith J, Fredericks G, Basson W, Nyoka M, Tshoma K. Transformation in cricket: Report submitted to the Honourable Minister of Sport and Recreation, Mr N Balfour. http://www.info.gov.za/otherdocs/2002/cricket. pdf (accessed 6 March 2009).

13. Cricket South Africa. Mission and vision. http://www.cricket.co.za/mission-and-vision.html (accessed 11 June 2009).

14. Shillinglaw AL. Bradman Revisited, The Legacy of Sir Donald Bradman Manchester: The Parrs Wood Press, 2003.

15. Coetzer $P$, Noakes TD, Sanders $B$, et al. Superior fatigue resistance of black South African distance runners. J Appl Physiol 1993;75:18221827.

16. Taliep MS, Gray J, Gibson ASC, Calder S, Lambert MI, Noakes TD. The effects of a 12-over bowling spell on bowling accuracy and pace in cricket 